\title{
Locus of control and persistence: Effects of skill and chance sets on session and postsession indices
}

\author{
LAWRENCE W. LITTIG and JACQUELINE A. SANDERS \\ Howard University, Washington, D.C. 20059
}

\begin{abstract}
The relationship of locus of control and skill and chance sets to session and postsession indices of persistence was assessed. Three indices of persistence were used: (a) time spent in an attempt to solve puzzles, (2) number of attempts to solve the puzzles, (3) willingness to return later for a similar experiment. The first two are experimental session indices, the latter, a postsession index. Neither of the session indices was related to locus of control or set. Willingness to return was strongly related to a skill set among internal subjects and to a chance set among external subjects. These differences are interpreted in terms of situational demand characteristics and extrinsic motivation.
\end{abstract}

In a study of the relationship between reflectionimpulsivity (Kagan, 1966) and locus of control (Rotter, 1966), on the one hand, and persistence, on the other hand, Finch, Kendall, Deardorff, Anderson, and Sitarz (1975) found that internal subjects persisted longer than external subjects on the Matching Familiar Figures test (Nowicki \& Strickland, 1973). Their subjects were emotionally disturbed children. The present study is an attempt to replicate this finding using a sample drawn from a normal college population and to examine certain hypotheses about the interactive effect of locus of control and persistence under conditions of the subject's belief that the outcome, success, or failure of task performance is controlled either by skill or by chance (Lefcourt, Lewis, \& Silverman, 1968; Phares, 1957). Three indices of persistence were used: (1) time spent in an attempt to solve puzzles, (2) number of attempts to solve the puzzles, and (3) willingness to agree to a request to return at another time to work again on similar puzzles. The first two indices are experimental session measures of persistence; the third index is a postexperimental session measure of persistence.

It was hypothesized that internality would be associated with greater persistence under a task set stressing skill determination of performance and that externality would be associated with greater persistence when chance is represented as the determinant of the outcome. These hypotheses are based upon the general notion that internality is a disposition reflective of a belief that one's own efforts will effect outcomes and that externality disposes one to rely on luck, fate, whim, that is, on chance.

Requests for reprints should be sent to Lawrence W. Littig, Department of Psychology, Howard University, Washington, D.C. 20059.

\section{METHOD}

\section{Overview}

Internal and external subjects worked on solvable and unsolvable puzzles under either chance or skill instructions for as long as they chose to do so. When the subjects stopped working, indicating that they were unable to solve all the puzzles, they were told the experiment was completed and were asked how well they thought they had done. They were then asked if they would be willing to return to work on similar puzzles. Measures of persistence were time spent on puzzles, number of puzzles attempted, and willingness to return.

\section{Subjects}

Subjects were 41 undergraduate students enrolled in introductory psychology courses at Howard University. The group was composed of 20 men and 21 women. These subjects were selected from an initial group of 60 subjects on the basis of scores obtained on the Rotter (1966) internality-externality (IE) scale. Subjects were selected who were in the lower (internal) and upper (external) thirds of the test group distribution. The mean IE scores for the internal $(n=21)$ and external $(n=$ $20)$ groups were 7.4 and 15.2 , respectively.

\section{Procedure}

Subjects were assigned randomly to each of two conditions. These conditions differed in instructional sets designed to induce the expectancy that the outcome of the experimental task could be controlled by the subject (skill condition) or that the outcome could not be influenced by the subject (chance condition). Twelve internal and 10 external subjects were randomly assigned to the skill condition; 9 internal and 10 external subjects were randomly assigned to the chance condition. The subjects worked on the perceptual reasoning test (PRT) described by Feather (1961). The PRT consists of four line drawings of geometrical figures, each of which was reproduced on $5.5 \times 8$ in. $(14 \times 20.3 \mathrm{~cm})$ Xerox paper. The subject's task was to trace over each figure with a pencil according to two rules: (1) The pencil could not be lifted from the paper; (2) no line could be traced over more than once. The drawings were available to the subject serially. The first two could be solved; the second two had no solution. The subject was seated at a table on which were four stacks of figures, 40 copies of one of the four figures in each stack. The subject could work to solve one figure by taking as many copies of the figure as desired to 
attempt to achieve a solution, or the subject could proceed to the next stack for a different figure, whether or not success had been realized with the previous attempt.

Instructions. Skill and chance sets for the task were induced by means of instructions that were identical for both conditions with the exception of the following paragraphs, the first of which was designed to induce a skill set and the second to induce a chance set.

(Skill) "The perceptual reasoning test is a test of your ability and skills. The items are of average difficulty and individual scores reflect ability. Some people do well and others poorly depending on their skill in perceptual reasoning."

(Chance) "The perceptual reasoning test is a controversial test and there are psychologists who argue that getting the solution is largely a matter of chance and luck since there are so many different ways of tracing the figures and combinations of directions to guess at. Many people are successful, yet many are unsuccessful."

The remainder of the instructions for both conditions were directions for doing the tasks and the rules to be followed.

Following the presentation of the instructions, the subject's attention was directed to a table of figures that purported to show performance norms for similar subjects. The table showed high percentages (between $81 \%$ and $91 \%$ ) of success for each of the puzzles. This was done to heighten the subject's task motivation by creating an initial high expectancy of success (Feather, 1961).

Persistence measures. Three indices of persistence were used. Two of these (total time on PRT and number of attempts) were obtained from the subjects within the boundaries of the "experimental session" as it was delimited for them. The third index, the subject's willingness to return for further work, was a postexperimental session measure of persistence obtained by asking the subject, ostensibly after the experiment had ended and following a "debriefing" in which the subject was asked to evaluate task performance and was given reassurance about his own performance, if the subject would be willing to return to try "a similar task at a later time?" Following the subject's response, the purpose of the research was explained.

During data collection, the experimenter did not know the locus of control designation of the subjects.

\section{RESULTS}

Session measures of persistence were assessed by means of two-way unweighted-means analyses of variance for total time spent on the PRT and for total number of puzzle attempts. A chi-square test of independence was performed on the postsession measure of willingness to return for a further session.

Table 1 presents the mean time in minutes spent on the PRT and the mean number of attempts as functions of locus of control and skill and chance sets. There were no significant effects for either the time or attempts measures. Indeed, there were contradictory trends for locus of control regardless of instructional set. Internal subjects spent more time than external subjects $[32.9$ vs. $27.2 \mathrm{~min} ; \mathrm{F}(1,38)=3.72, \mathrm{p}<.10]$, yet made fewer attempts $[14.7$ vs. $15.3, F(1,38)=2.61$, $\mathrm{p}<.20]$

Table 2 presents the frequencies of subjects agreeing or not agreeing to return for further experimentation. Neither instructional set nor locus of control produced a significant effect independently $\left[\chi^{2}(1)=1.88, p<.20\right.$,
Table 1

Persistence Time (in Minutes) and Number of Attempts for Internal and External Subjects Under Skill and Chance Sets

\begin{tabular}{|c|c|c|c|c|c|c|}
\hline \multirow[b]{3}{*}{ Orientation } & \multicolumn{4}{|c|}{ Locus of Control } & & \\
\hline & \multicolumn{2}{|c|}{ Internal } & \multicolumn{2}{|c|}{ External } & \multicolumn{2}{|c|}{ Total } \\
\hline & Mean & SD & Mean & SD & Mean & SD \\
\hline \multicolumn{7}{|l|}{ Skill } \\
\hline Time & 33.4 & 12.5 & 26.7 & 11.0 & 30.4 & 12.1 \\
\hline Attempts & 17.0 & 13.2 & 18.1 & 11.0 & 17.6 & 11.9 \\
\hline \multicolumn{7}{|l|}{ Chance } \\
\hline Time & 32.2 & 9.7 & 27.7 & 9.9 & 29.9 & 9.8 \\
\hline Attempts & 12.4 & 9.0 & 12.4 & 4.1 & 12.4 & 6.7 \\
\hline \multicolumn{7}{|l|}{ Total } \\
\hline Time & 32.9 & 11.2 & 27.2 & 10.2 & 30.1 & 10.9 \\
\hline Attempts & 14.7 & 11.5 & 15.3 & 8.6 & 15.0 & 10.1 \\
\hline
\end{tabular}

Note-For internal skill, $n=12$, for internal chance, $n=9$, for external skill, $n=10$, for external chance, $n=10$.

Table 2

Locus of Control and Frequency of Agreeing (Yes) or Not Agreeing (No) to Return for Further Research Participation

\begin{tabular}{|c|c|c|c|c|c|c|}
\hline \multirow[b]{3}{*}{ Orientation } & \multicolumn{4}{|c|}{ Locus of Control } & & \\
\hline & \multicolumn{2}{|c|}{ Internal } & \multicolumn{2}{|c|}{ External } & \multicolumn{2}{|c|}{ Total } \\
\hline & Yes & No & Yes & No & Yes & No \\
\hline Skill & 12 & 0 & 2 & 8 & 14 & 8 \\
\hline Chance & 1 & 8 & 7 & 3 & 8 & 11 \\
\hline Total & 13 & 8 & 9 & 11 & 22 & 19 \\
\hline
\end{tabular}

Note $-\chi^{2}(3)=22.00, p<.001$.

and $\chi^{2}(1)=1.16, \mathrm{p}<.30$, respectively]. A highly significant interaction was present, however $\left[\chi^{2}(3)=\right.$ $22.00, \mathrm{p}<.001]$. All internal subjects given skill instructions agreed to return, but only one subject given chance instructions indicated a willingness to return $\left[\chi^{2}(1)=17.05, p<.001\right]$. Reverse relationships obtained for external subjects; under skill instructions, the majority did not wish to return, and under chance instructions, the majority was willing to return $\left[\chi^{2}(1)=4.95, p<.05\right]$. The hypothesized interaction between locus of control and type of set was strongly supported by the postsession behavior of the subjects.

\section{DISCUSSION}

The study provides mixed evidence of the interrelationship between locus of control, skill or chance set, and persistence. It suggests that a relatively conventional experimental method of assessing a dispositional tendency may have its power considerably reduced, even negated, by qualities inherent in the experimental situation, by its demand characteristics (Orne, 1962), so that variables that, in fact, are affecting the subject are prevented from manifesting themselves. Only after the apparent termination of the experiment, when the subject had completed the work and fulfilled the obligation to the experimenter, did behavior consistent with the hypotheses emerge. It appears that the negative results from data collected in the experimental sessions resulted from unanticipated attributes inherent to the method. Puzzles are generally interesting. 
Subjects, regardless of their locus of control and the experimental manipulations they experienced, appear to have been under a high level of motivation to perform successfully. Termination of the experimental session ended the extrinsic motivation (Atkinson \& Birch, 1978) associated with the immediate task, and the postsession measure was then able to reveal the influence of the study variables.

\section{REFERENCES}

Atkinson, J. W., \& Birch, D. Introduction to motivation. New York: Van Nostrand, 1978.

Feather, N. T. The relationship of persistence at a task to expectation of success and achievement-related motives. Journal of Abnormal and Social Psychology, 1961, 63, 552-561.

Finch, A. J., Kendall, P. C., Deardorff, P. A., Anderson, J., \& Sitarz, A. M. Reflection-impulsivity, persistence behavior, and locus of control in emotionally disturbed children. Journal of Consulting and Clinical Psychology, 1975, 43, 748.
KAGAN, J. Reflection-impulsivity: The generality and dynamics of conceptual tempo. Journal of Abnormal Psychology, 1966, 71, 17-24.

Lefcourt, H. M., Lewis, L., \& Silverman, I. W. Internal versus external control of reinforcement and attention in a decision-making task. Journal of Personality, 1968, 36, 663-683.

Nowicki, S., JR., \& Strickland, B. R. A locus of control scale for children. Journal of Consulting and Clinical Psychology, 1973, 40, 148-154.

ORNE, M. On the social psychology of the psychological experiment: With particular reference to demand characteristics and their implications. American Psychologist, 1962, 17, 776-783.

Phares, E. J. Expectancy changes in skill and chance situations. Journal of Abnormal and Social Psychology, 1957, 54, 339-342.

RotTer, J. B. Generalized expectancies for internal versus external control of reinforcement. Psychological Monographs, 1966, 80(1, Whole No. 609).

(Received for publication March 26, 1979.) 